\title{
Non-microbiological turbidity of beer: Part 2 - a case study
}

\author{
Jana Olšovská*, Petra Kubizniaková, Martin Slabý, Lucie Kyselová \\ Research Institute of Brewing and Malting, Lípová 511/15, \\ 120 00, Prague 2, Czech Republic \\ * corresponding author: olsovska@beerresearch.cz
}

\begin{abstract}
Non-microbial beer turbidity of lager beers often indicates a technological problem. Therefore, the occurrence of permanent haze in filtered and stabilized beer should not be underestimated. In this study, practical examples from industrial breweries, where several types of non-microbiological haze of colloidal were identified, are presented. These examples of haze were caused by slightly different factors, and as a result, they had a different microscopic image. It is often accompanied by mechanical impurities and sometimes by microorganisms that function as nucleation centers. Moreover, a very interesting example of almost brilliant permanent beer haze caused by the destruction of yeast cells with the following pouring intracellular contents of cells into beer is introduced. This phenomenon, which could be called "precedent", was caused by a bad physiological condition of yeasts cells and inappropriately chosen yeast separation technology.
\end{abstract}

Keywords: beer, colloidal turbidity, protein turbidity, protein-polyphenol turbidity, haze, microscopic analysis, image analysis

\section{Introduction}

Although it would seem that the problem of turbidity in beer is well studied and described in the literature, in practice we still encounter new examples of non-microbiological haze of turbidity that are not frequent. Therefore, this "never-ending story" still needs to be dealt with. The first part of our article, which has been recently published, summarized the theory of microbiological turbidity and introduced common practical examples (Olšovská et al., 2021). The second part presents interesting and sometimes very unexpected examples from practice that were investigated in commercial beer samples with different turbidity problems.

\section{Materials and methods}

The haze identification was performed using a combination of several known and routine methods as described below.

Turbidity was analyzed according to EBC 9.29 (2015).
Microscopy analysis. Firstly, $100 \mathrm{~mL}$ of a sample was centrifuged for $30 \mathrm{~min}$ at $3000 \mathrm{rpm}$. Subsequently, the obtained supernatant was microscopically observed (630× magnification AXIOSKOP, Zeiss), recorded using the Imaging Source DMK 23UX174 camera, and documented by image analysis NIS Elements (ver. 5.10. for Windows 10, Laboratory Imaging).

Microscopic detection of protein component by staining the colloid by eosin Y. A stock solution of eosin Y was prepared by dissolution of $1 \mathrm{~g}$ of eosine in $20 \mathrm{~mL}$ of distilled water and $80 \mathrm{~mL}$ of pure ethanol (p.a., 95\% v/v). A working solution was prepared by mixing $25 \mathrm{~mL}$ of the stock solution, $75 \mathrm{~mL}$ of ethanol $(80 \% \mathrm{v} / \mathrm{v})$, and $0.5 \mathrm{~mL}$ of glacial acetic acid.

Eosin was dropped on a slide on which the tested suspension was applied, it was covered with a cover glass, and microscopical analysis was performed. The dyed protein parts were visible as pink.

Dissolving protein-polyphenol colloids by $\mathrm{KOH}$ was performed using $2 \%$ sodium hydroxide solution. 
Microbial analysis. Identification of lactic acid bacteria and coliforms was performed according to EBC 4.3.3.1 (2011) and EBC 4.4.2 (2011), respectively.

The detection of yeasts was performed using wort agar with tetracycline $(50 \mathrm{mg} / \mathrm{L})$, which was cultivated for 2 days at $26 \pm 1^{\circ} \mathrm{C}$.

Iodine value corresponding to the concentration of dextrins was photometrically analyzed according to MEBAK 2.3 (2011).

Total polyphenols were spectroscopically analyzed according to EBC 9.11 (2002).

Proteins with molecular weight over 5,000 Da were determined according to Bradford (Bradford, 1976) after in-house optimization. Firstly, the dye of Coomassie Brilliant Blue G 250 was prepared by its dilution (15 mg) in $10 \mathrm{~mL}$ of ethanol and $20 \mathrm{~mL}$ of phosphoric acid (p.a. 85\%) while stirring on a magnetic stirrer. Next, absorbance of blank determination $(5 \mathrm{~mL}$ of the dye with $0.5 \mathrm{~mL}$ of distilled water) was checked and it must have ranged from 0.440 to 0.460 . Further, the beer sample was prepared by removing carbon dioxide, filtrating using filtration paper (grade 388), and five times diluting by ultrapure water prepared by the MilliQ system (Millipore, USA). Finally, $5 \mathrm{~mL}$ of the dye was added to a tube with $0.5 \mathrm{~mL}$ of the diluted beer sample and was immediately mixed. The measurement at $600 \mathrm{~nm}$ was performed after 15 min (in triplicate). Distilled water was used as a reference sample.

The final concentration of proteins was calculated according to the formula:

$$
c_{C B B}(m g / 100 m L)=\left(A_{S}-A_{B}\right) * D * F,
$$

where $c_{C B B}$ is the concentration of proteins, $A_{S}$ is the absorption of the sample, $A_{B}$ is the absorption of the blank sample (the dye), $D$ is dilution, and $F$ is the factor 27.2331, which was derived from calibration dependence constructed using proteins isolated from wort and beer.

Oxalates and calcium were analyzed according to MEBAK 2.22.2 (2013) and EBC 9.19 (2002), respectively.

Polysaccharides higher than DP 10 were determined according to Jurková et al. (2014) as the difference between the concentration of total saccharides (expressed as the concentration of glucose) and the sum of glucose and higher oligomers with up to DP 10 (DP is the degree of polymerization; DP10, for example, is formed by 10 molecules of glucose).

\section{Results and discussion}

In the following text, five practical examples of haze and the procedure of its identification are described.

No. 1. In filtered pale lager beer increased haze (1.41.7 EBC) which was almost invisible by the naked eye and did not increase further was identified immediately after filtration. The particles causing haze sedimented slowly and their separation was quite demanding. The first microscopic image of separated haze from the final beer looked primarily like massive microbiological contamination with a small amount of higher colloidal particles (see Figures 1a, 1b). Escaped kieselguhr and very small mechanical particles were also visible (see Figure 1c). However, microbial contamination was not subsequently determined by microbial analysis.

Further, chemical analyses such as iodine value, the content of polysaccharides higher than DP 10, and total polyphenols were performed. Quite a high concentration of polysaccharides (higher than $3 \mathrm{~g} / 100 \mathrm{~mL}$ ) was found. Therefore, an assumption that haze is formed by saccharide complexes, possibly by rests of starch corns or by saccharides originating from grain bran, was considered. Also, the very high iodine value (0.85) can indicate the increased concentration of higher oligosaccharides. Both these results could indicate a susceptibility of beer to carbohydrate turbidity. Moreover, the concentration of proteins with a molecular weight of over 5,000 Da was $37 \mathrm{mg} / 100 \mathrm{~mL}$, thus also an increased value. The concentration of total polyphenol was very low, namely $90 \mathrm{mg} / \mathrm{mL}$.

Since the conclusion that haze is formed by untypical polysaccharide particles was not convincing at all, new experiments were conducted. After a repeated consultation with technologists and examination of beer before filtration, a new hypothesis was stated: The cause of haze is caused by damaged yeasts used in repeated cycles. The confirmation of this hypothesis is shown in Figures $1 \mathrm{~d}$ and $1 \mathrm{e}$ where destructed yeast cells with interrupted cell walls and overflowing intracellular content are well visible. Besides, the intracellular content of the cells itself passed to beer increased iodine value or, in other words, the content of high molecular weight (non-saccharified) saccharides. Therefore, unlike other common colloidal haze, this haze did not increase in time. Furthermore, crystals of oxalates were also identified in yeasts separated from beer before filtration (see Figure 1e). It is important to highlight that until the beer was analyzed after technological filtration, it was not possible to determine the cause of turbidity. Hence, a microscopic image of beer after technological separation of yeasts is shown in Figure 1f. Also, nothing could be ascertained from such a finding. 
The fact that haze was caused by an intracellular content of destructed yeast cells which were in a bad physiological condition corresponds with a constant value of haze (1.4-1.7 EBC), a very high iodine value

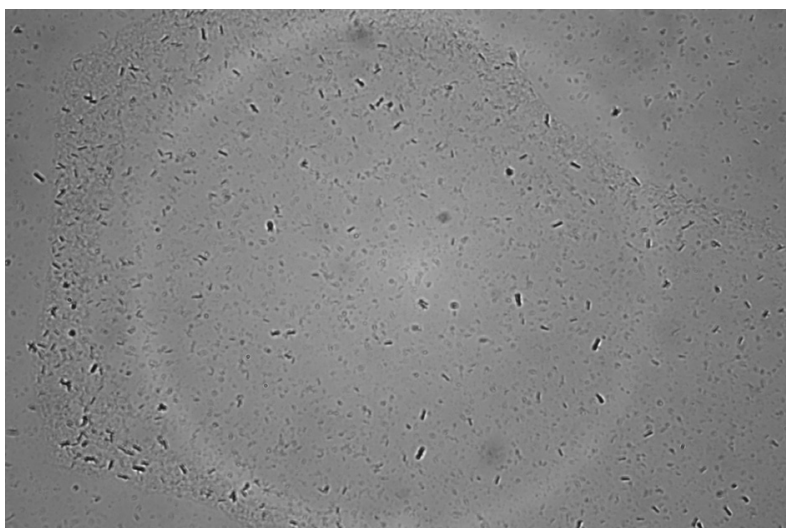

Figure 1a Microscopic image of separated haze (very small colloidal particles resembling microbial contamination

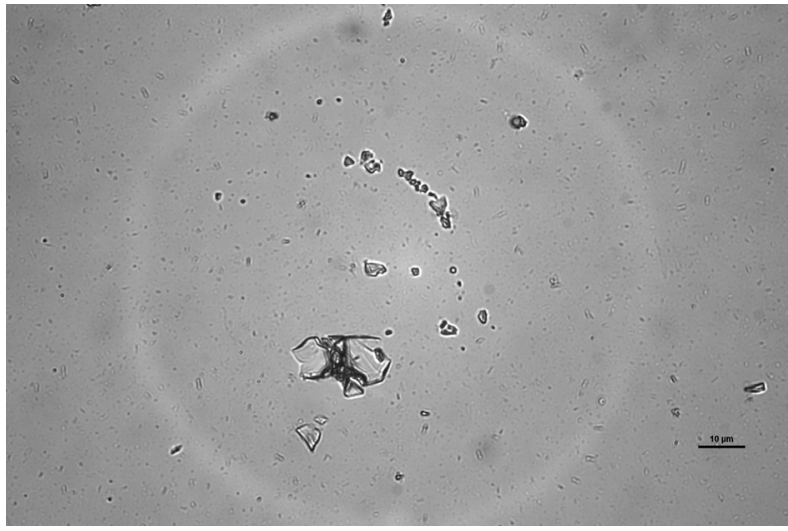

Figure 1c Contaminating mechanical and kieselguhr particles

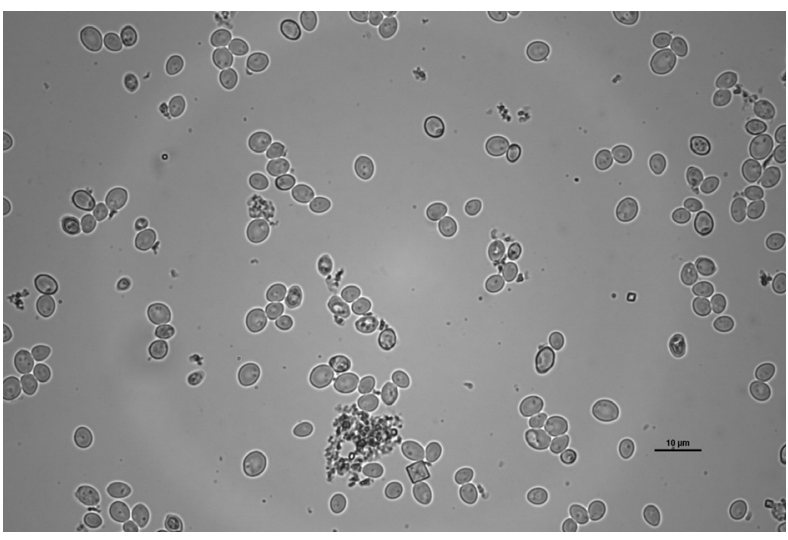

Figure 1e Destructed yeast cells with interrupted cells in beer together with crystals of oxalates (before the technological separation of yeasts)
(0.85) indicating a high concentration of unfermented saccharides, and the increased concentration of high-molecular proteins. In any case, the study of this phenomenon will continue.

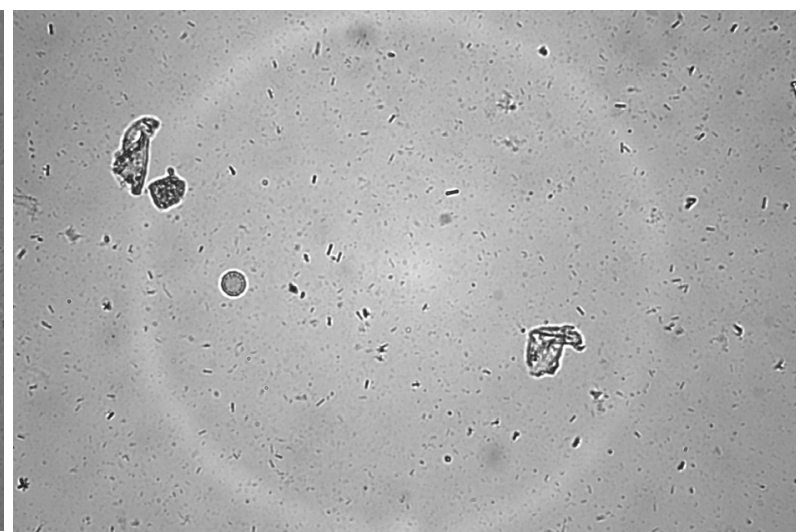

Figure 1b Microscopic image of separated haze (larger colloidal particles and kieselguhr earth against a background of very small dense turbidity)

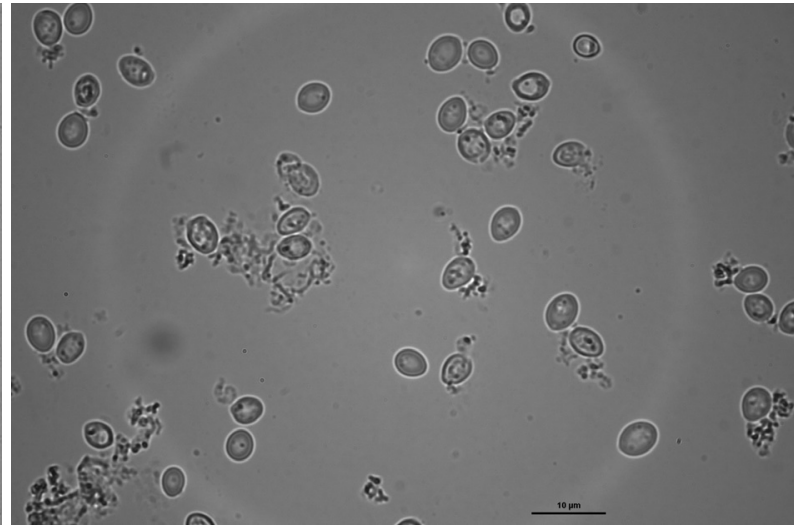

Figure 1d Destructed yeast cells with interrupted cells in beer (before the technological separation of yeasts)

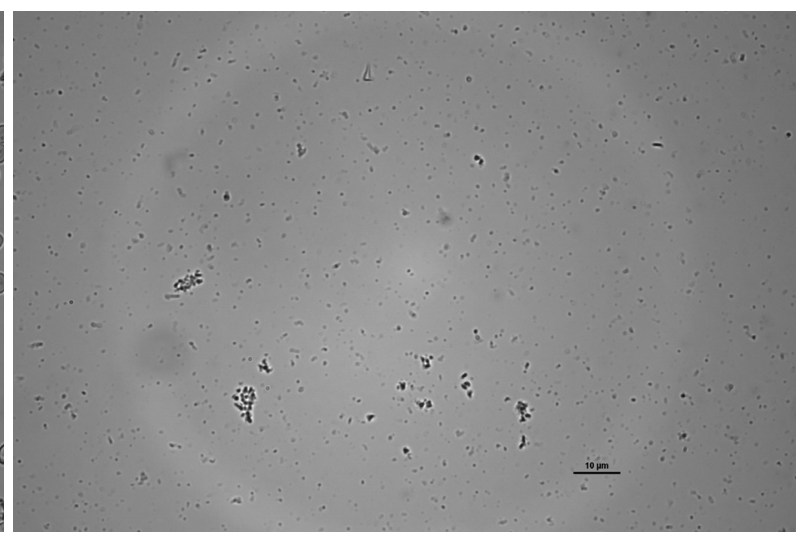

Figure 1f Beer haze after the technological separation of yeasts 
No. 2 is not as complicated as the previous example, but it is certainly worth mentioning it. A non-alcoholic beer sample had light flake-like haze (about 3 EBC) which sedimented medium-fast and formed gentle sediment at the bottom of the bottle. Microscopic analysis revealed well visible particles of a colloid character resembling a veil with a solid core that increased in time until a maximum size of about $250 \mu \mathrm{m}$. After dying the colloid by eosin, pink color was obtained confirming the protein presence. Subsequently, the determination of total polyphenols, proteins with a molecular weight of over 5,000 Da, and iodine value was performed. Whereas the concentration of total polyphenols was corresponding to stabilized non-alcoholic beer ( $86 \mathrm{mg} / \mathrm{L})$, the content of proteins was high $(40 \mathrm{mg} / 100 \mathrm{~mL})$. When a little bit higher iodine value is also considered (0.34), a formation of permanent haze is very probable. Thus, this haze, which is demonstrated in Figures 2a and 2b, was identified as colloidal haze formed predominantly by proteins.

No. 3 is an example of "complex" haze. Pale lager beer had visible haze (3.8-4.1 EBC) and compact sediment at the bottom of the bottle. In the sediment there were visible dark particles. Firstly, microscopic analysis was performed and particles higher than $300 \mu \mathrm{m}$ were found. After dying with eosin, protein was proved. Furthermore, a large number of microorganisms were observed, both yeast and bacteria (see Figure 3a), which also formed compact clusters. In addition to organic particles, crystals of calcium oxalate (see Figure 3b), micro-shards, fibrous material (see Figure 3c), and larger amounts of escaped kieselguhr and PVPP (Figure 3d) were discovered. The dark particles were mostly inor-
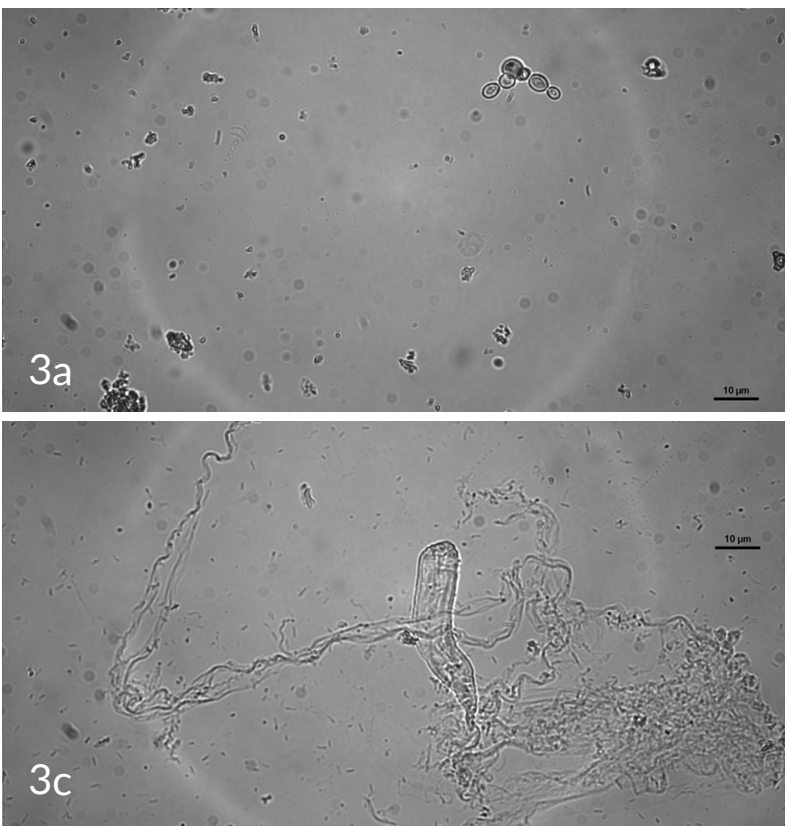

Figure 3a The mixture of colloid and yeasts Figure $3 \mathrm{~b}$ The mixture with oxalate crystals
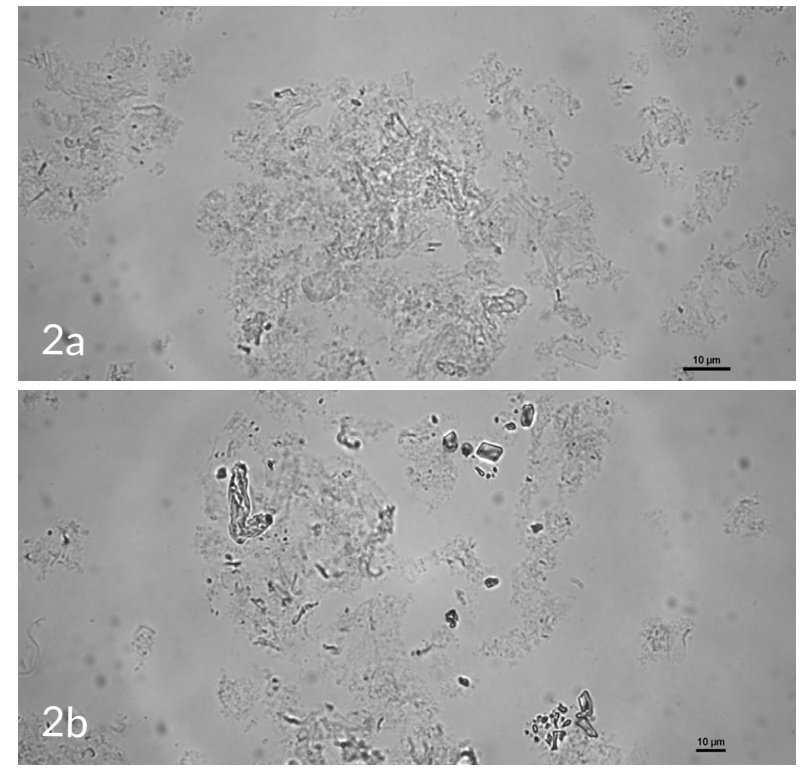

Figure $2 \mathrm{a}$ and $2 \mathrm{~b}$ Colloidal haze separated from non-alcoholic beer

ganic substances such as PVPP and also there was a smaller part of organic compounds that dissolved in $\mathrm{KOH}$. Finally, the concentration of total polyphenols and proteins with the molecular weight of over 5,000 Da was determined, resulting in $146 \mathrm{mg} / \mathrm{L}$ and $42 \mathrm{mg} / 100 \mathrm{~mL}$, respectively.

Considering the results, the studied beer was very unstable and had a great turbidity potential due to many inorganic particles and microorganisms that represented nucleation centers for colloid haze formation. In this case, it should be noted that the presence of inorganic matter (filter aids) indicates a problem with the filtration technology (Steiner et al., 2010).
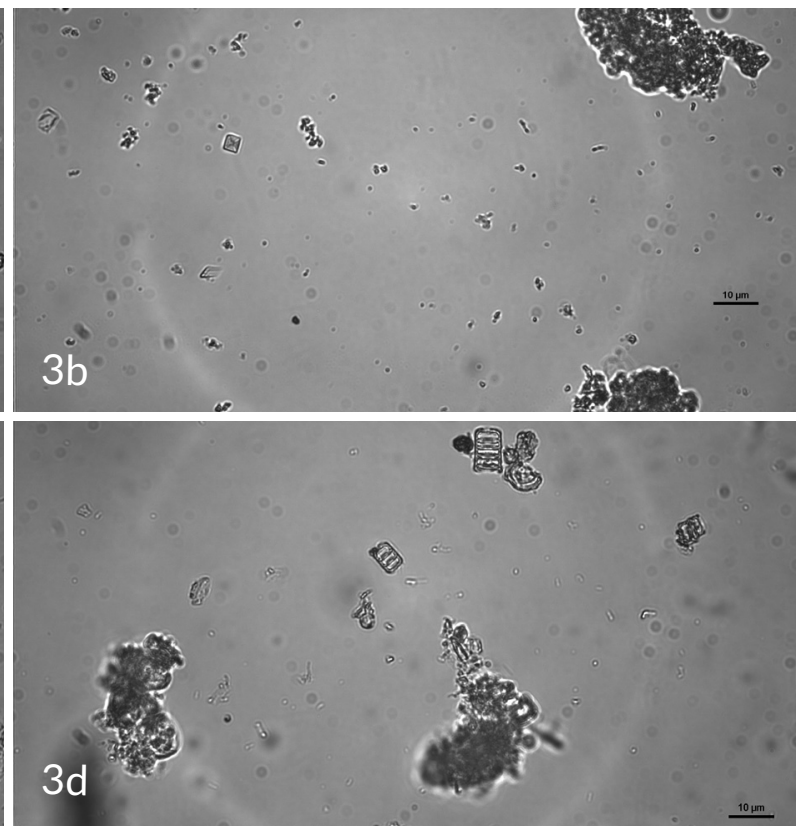

Figure 3c Fibrous mechanical impurities

Figure 3d Kieselguhr and particles of PVPP coated by colloid 
No. 4 Another example of colloidal haze is demonstrated in Figures $4 \mathrm{a}$ and $4 \mathrm{~b}$. Haze of this pale lager beer sample resembling a "veil" was almost brilliant (around 1 EBC) and nearly did not form sediment spontaneously. Microscopic analysis of the image showed a large number of small particles with a size of about 1-2 $\mu \mathrm{m}$ (see Figure 4a) which gradually aggregated into large colloidal formation with the size of up to $200 \mu \mathrm{m}$ (Figure 4b). As this formation was soluble in $\mathrm{KOH}$ and dyeable by eosin, protein presence was proved. A colloidal character of haze was also determined by chemical analysis, where the concentration of total polyphenols (153 mg/L) slightly increased and the concentration of proteins with molecular weight over 5,000 Da (40 mg/100 mL) was very high. Furthermore, fibrous formation most likely coming from filter materials or other "foreign substances" was also identified (see Figure 4a).

No. 5 The last example of haze in pale lager with visible haze (> 2 EBC) was formed by a well visible "veil" together with quite big particles. Microscopic analysis of the image showed colloidal particles higher than $100 \mu \mathrm{m}$. Their polyphenol-protein character was verified using dying with eosin. Simultaneously, the particles were perfectly soluble in $\mathrm{KOH}$. After microbiological analysis which excluded microbial contamination, this haze was classified as protein-polyphenol haze. During finding a solution to this turbidity problem, gradual clustering of small particles to big formations was successfully microscopically captured (see Figures 5a, 5b, 5c, and 5d).
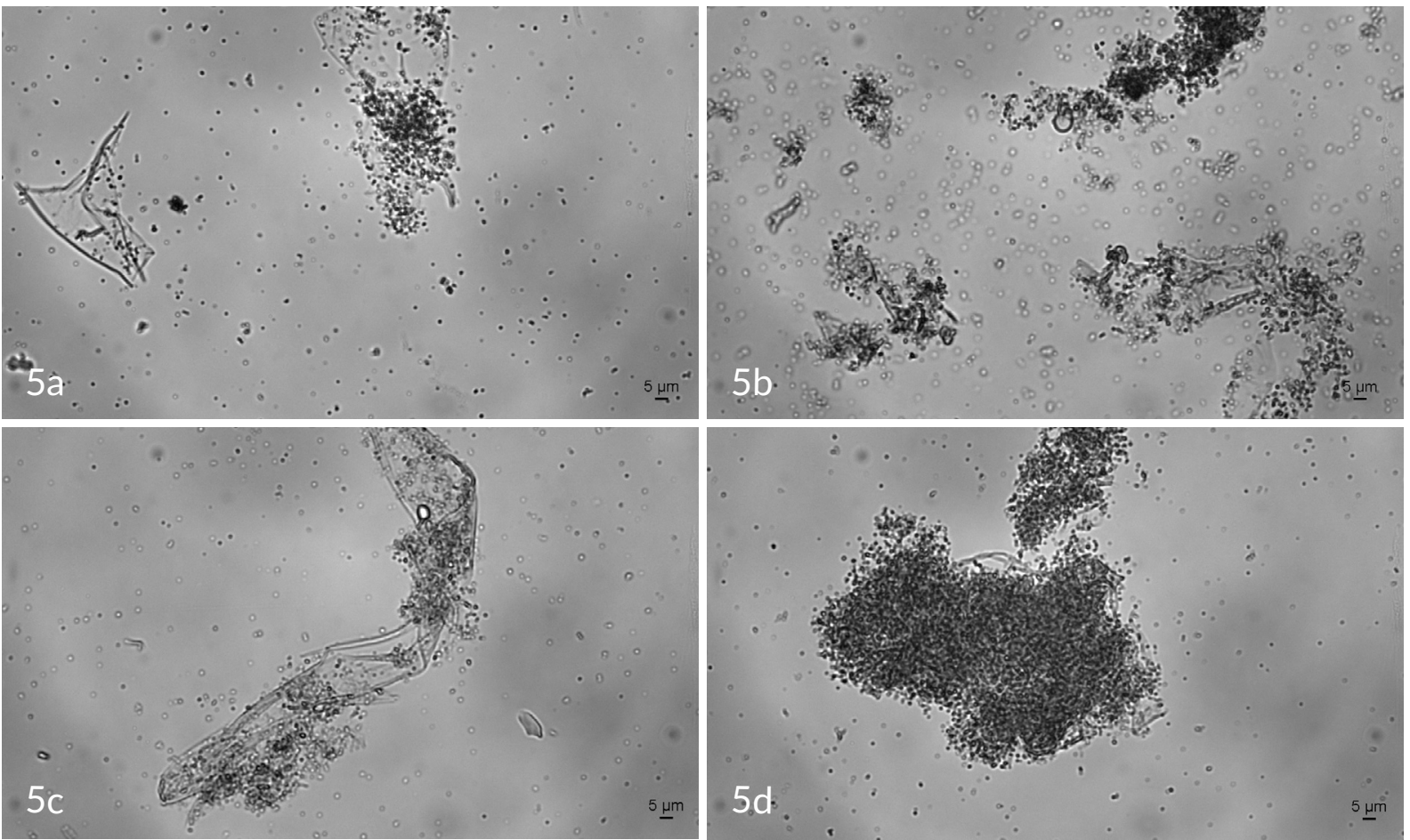

Figures 5a, 5b, 5c, 5d Formation and gradual growth of colloidal turbidity particles 


\section{Conclusion}

Chemical and microbial stability of filtered lager beers are relevant factors in determining the shelf life of beer. The measurement of turbidity is, therefore, an important step for both, checking a visual reason and indicating more serious contamination. Generally, non-microbiological haze can be classified as cold, permanent, and turbidity caused by foreign particles.

The examples of non-microbiological turbidity above were caused (except Example No. 1) by either foreign particles, raw material substances of beer, or combinations thereof. Further, proteins and polyphenols made up a major part of the turbidity colloids and, mostly proteins with molecular weight over 5,000 Da exceeded the limit concentration $(25 \mathrm{mg} / 100 \mathrm{~mL})$ for haze formation (Olšovská et al, 2021). Even if the given examples of beer turbidity (No. 2 - No. 5) were caused mainly by permanent colloidal haze, each example was caused by a slightly different source and, most importantly, had a different microscopic image, which was sometimes atypical at first glance. Sometimes, mechanical particles were part of non-biological turbidity that could have represented a nucleation center for colloid formation. In addition to this fact, mechanical impurities such as filter aids could indicate a problem with filtration technology.

Finally, the example No. 1 is, by our experience, a not well studied phenomenon yet. This type of haze is not formed during beer aging, however, by pouring intracellular contents of yeasts cells into beer. It was most likely caused by the bad physiological condition of yeasts cells and inappropriately chosen yeast separation technology.

\section{Acknowledgement}

This study was supported by the Ministry of Agriculture of the Czech Republic within the institutional support No. MZE-R01918

\section{REFERENCES}

Bradford, M. M. (1976). A rapid and sensitive method for the quantitation of microgram quantities of protein utilizing the principle of protein-dye binding. Analytical Biochemistry, 72, 248-254. https://doi. org/10.1006/abio.1976.9999

EBC 4.3.3.1. (2011). Analytica EBC. Lactic Acid Bacteria. Fachverlag Hans Carl, Nürnberg. Retrieved from https://brewup.eu/ebc-analytica

EBC 4.4.2. (2011). Analytica EBC. Escherichia coli and Coliform Bacteria. Fachverlag Hans Carl, Nürnberg. Retrieved from https://brewup.eu/ ebc-analytica

EBC 9.11. (2002). Analytica EBC. Total Polyphenols in Beer by Spectrophotometry. Fachverlag Hans Carl, Nürnberg. Retrieved from https://brewup.eu/ebc-analytica

EBC 9.19. (2002). Analytica EBC. Calcium in Beer by Atomic Absorption Spectrophotometry. Fachverlag Hans Carl, Nürnberg. Retrieved from https://brewup.eu/ebc-analytica

EBC 9.29. (2015). Analytica EBC. Haze in Beer: Calibration of Haze Meters. Fachverlag Hans Carl, Nürnberg. Retrieved from https://brewup.eu/ ebc-analytica

Jurková, M., Čejka, P., Štěrba, K., Olšovská, J. (2014). Determination of total carbohydrate content in beer using its pre-column enzymatic cleavage and HPLC-RI. Food Analytical Methods, 7(8), 1677-1686. https://doi.org/10.1007/s12161-014-9805-y

MEBAK 2.3. (2011). Photometric Iodine Test. In J. Fritz (Ed.), MEBAK - Wort, Beer, Beer-based Beverages. Germany: Freising-Weihenstephan.

MEBAK 2.22.2. (2013). Oxalate by Ion Chromatography with Conductivity detection. In J. Fritz (Ed.), MEBAK - Wort, Beer, Beer-based Beverages. Germany: Freising-Weihenstephan.

Olšovská, J., Štěrba, K., Slabý, M., Vrzal, T. (2021). Novel method for determination of heterocyclic compounds and their impact in brewing technology. Kvasny Prumysl, 67(2), 417-427. https://doi. org/10.18832/kp2021.67.417

Steiner, E., Becker, T., Gastl, M. (2010). Turbidity and haze formation in beer - insights and overview. Journal of the Institute of Brewing, 116(4), 360-368. https://doi.org/10.1002/j.2050-0416.2010.tb00787.x 